\title{
Valsalva maneuver procedures in the diagnosis of right-to-left shunt by contrast-enhanced transcranial doppler using agitated saline solution with blood as a contrast agent
}

\author{
Marcos Christiano Lange, Viviane Flumignan Zétola, \\ Elcio Juliato Piovesan, Lineu César Werneck
}

\begin{abstract}
Objective: To compare two different timings for the performance of the Valsalva maneuver (VM) using an infusion of agitated saline solution with blood as contrast agent (CA) to right-to-left shunt (RLS) screening. Method: 42 patients were submitted to a standardized contrast-enhanced transcranial doppler (CTCD) to screen for right-to-left shunt (RLS). cTCD technique was done with two different moments of the VM: [1] the CA injection during the VM (CAduringVM test); [2] the CA injection before the VM (CApreVM test). Results: Positive MCA tests were observed in 47 (56\%) CAduringVM tests and in 50 (59.5\%) CApreVM tests, $p=0.64$. There was an almost perfect agreement for the positive tests between the CAduringVM and CApreVM test, $r_{s}=0.829$ ( $95 \% \mathrm{Cl} 0.61-1.00, p<0.001$ ). Conclusion: The present study demonstrates that there is no significant difference in the results of RLS screening by cTCD when two different moments of VM were done.

Key words: contrast media, paradoxical embolism, microbubbles, transcranial doppler, ultrasonography, Valsalva maneuver.
\end{abstract}

Manobra de Valsalva no diagnóstico de embolia paradoxal pelo doppler transcraniano contrastado com o uso de solução salina agitada associada a sangue como meio de contraste

\section{RESUMO}

Objetivo: Comparar dois momentos diferentes da manobra de Valsalva (MV) com o uso de solução salina com sangue como meio de contraste (MC) para investigação de embolia paradoxal (EP). Método: 42 pacientes foram submetidos a protocolo padronizado de DTCc com a MV em dois momentos diferentes: [1] injeção do MC durante a MV (teste ACduranteMV); [2] injeção de MC antes da MV (teste ACpreMV). Resultados: Exames positivos foram observados em 47 (56\%) ACMs testes ACduranteMV e 50 (59.5\%) testes ACpreMV, $p=0.64$. Houve uma correlação quase perfeita entre ambos os testes, $r_{s}=0.829$ (95\% Cl 0.61-1.00, $p<0.001)$. Conclusão: $O$ presente estudo demonstra que não existe diferença significativa na positividade de EP pelo DTCc quando são comparados dois momentos diferentes da MV.

Correspondence

Marcos Christiano Lange Hospital de Clínicas

Serviço de Neurologia Rua General Carneiro $181 / 4^{\circ}$ andar 80060-900 Curitiba PR - Brasil

E-mail: lange@ufpr.br

Received 20 May 2009

Receveid in final form 2 September 2009 Accepted 8 September 2009
Palavras-chave: meios de contraste, embolia paradoxical, microbolhas, doppler transcraniano, ultra-som, manobra de Valsalva.
Contrast-enhanced transcranial doppler (CTCD) is a reliable and reproducible screening method for right-to-left shunt
(RLS) diagnosis ${ }^{1,2}$. The Valsalva maneuver (VM) increases the positive results of standardized cTCD studies by $45 \%$ by increas-
Cerebrovascular Diseases Unit, Neurology Division, Internal Medicine Department, Hospital de Clínicas, Universidade Federal do Paraná, Curitiba PR, Brazil. 
ing the right atrial pressure to facilitate or reveal an intermittent RLS via a patent foramen ovale (PFO) $)^{2,3}$.

Previous studies have demonstrated that the ideal time to perform the VM is five seconds after contrast agent (CA) infusion, but these studies were done preferentially with agitated saline solution (AS) or a galactose-based $\mathrm{CA}^{1,3,4}$. Studies used a small sample of a patient's own blood to obtain an agitated saline solution with blood (ASb) as a means of increasing the number of microbubbles (MBs) generated compared to $\mathrm{AS}^{5}$.

The aim of this study was to compare two different timings of the VM with the infusion of ASb as a CA.

\section{METHOD}

We evaluated 42 patients in the Laboratory of Neurosonology for RLS diagnosis. All of the subjects gave their written informed consent. Clinical and neurological evaluations were done in all of the cases and none patient had an extracranial or an intracranial stenosis evaluated by ultrasonography. There were 32 patients with ischemic stroke, 5 with transitory ischemic attacks, and 5 with migraine with aura. The local ethics committee approved this study.

The cTCD (doppler-Box DWL, Singen, Germany) procedures were performed with the patients in a supine position. Two 2-MHz pulsed doppler transducers were fixed with a head frame (DiaMon DWL, Singen, Germany) and insonated both middle cerebral artery (MCA) main stems through the temporal window at a depth of 50 to $65 \mathrm{~mm}$ to capture a small sample volume of $8 \mathrm{~mm}$ in length with two spectral gates $8 \mathrm{~mm}$ apart and the Mmode (32 sample gates in each channel). A 256-point fast Fourier transform analysis was used.

The CA was composed of a mixture of $8 \mathrm{~mL}$ saline, 1 $\mathrm{mL}$ air, and $1 \mathrm{~mL}$ of the patient's blood. Before the infusion, the solution was prepared by agitating the mixture between two $10 \mathrm{ml}$ syringes 10 times through a three-way tap connected to an 18 gauge intravenous catheter inserted in a right antecubital superficial vein. The distance from the catheter to the syringes was less than $10 \mathrm{~cm}$. The CA was injected in 5 seconds into the antecubital vein.

All of the patients were submitted to two different methods, and each was repeated twice with the ASb: [1] the VM was maintained for at least 10 seconds, with the CA infusion five seconds after the beginning of the VM (CAduringVM test); [2] the VM was maintained for at least five seconds, with the CA infusion five seconds before the beginning of the VM (CApreVM test).

The VM effectiveness was monitored by a $25 \%$ decrease in the MCA flow velocity and a mouthpiece connected to a manometer. The subjects were trained before the tests, and they were instructed to maintain an expiratory pressure of $40 \mathrm{mmHg}$. A small leak in the tubing

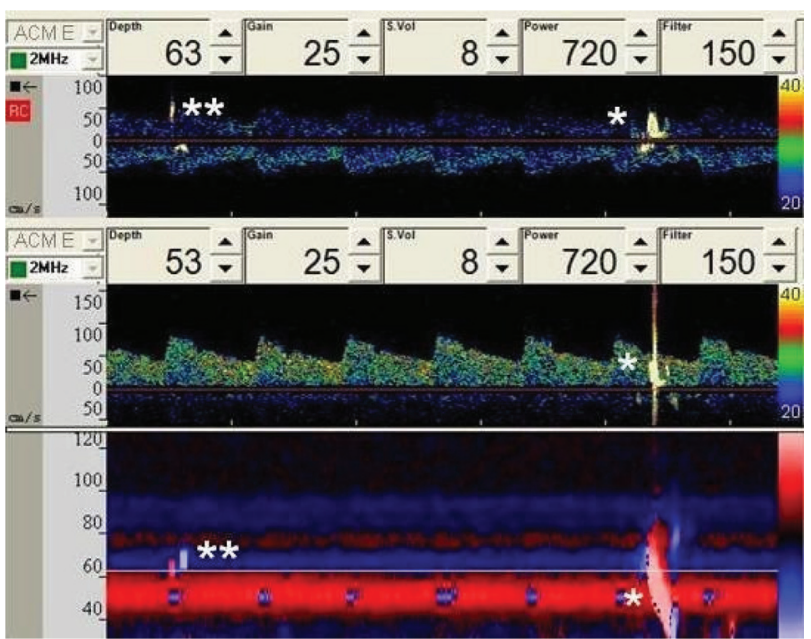

Fig 1. A positive embolus track (ET) $\left(^{*}\right)$ in the left middle cerebral artery is visualized in both spectral gates (depth=63 $\mathrm{mm}$ and 53 $\mathrm{mm}$ ) and the M-mode, and an anterior cerebral artery ET $\left(^{* *}\right)$ is visualized only on the proximal spectral gate (depth=63 $\mathrm{mm}$ ) and the M-mode.

prevented the subjects from maintaining the pressure by closing the glottis, and care was taken to prevent deep breathing before and after the release of the strain ${ }^{6}$.

All of the tests were 60 seconds in duration, and they were recorded for later interpretation and quantification offline. There was an interval of three minutes between each of the tests.

A test was considered positive when at least one embolus track (ET) with previously defined criteria was detected on both of the spectral gates displays and the Mmode of at least one of the monitored MCAs ${ }^{1,7}$. The ET criteria were a unidirectional, typically visible and audible, short duration, high-intensity signal within the doppler flow spectrum with a movement toward the MCA as time progresses and a positively-sloped track in the Mmode image (Fig 1) 1 1,7-9.

The ET counts were obtained individually for each MCA during an offline analysis. The highest count obtained with ASb in each VM procedure was considered for analysis. The studies were classified based on previous criteria and defined as: negative $=$ no $E T$ observed; grade $\mathrm{I}=1-10 \mathrm{ETs}$, and grade $\mathrm{II}>10 \mathrm{ETs}^{2}$.

The latency time, in seconds, between the CA injection and the detection of the first ET were analyzed in each MCA. The duration, in seconds, of the ET passage after the CA injection was evaluated in all of the tests by measuring the time between the first and the last ET in each of the MCAs tested.

The statistical analyses were performed with SPSS 12.0 software (SPSS Inc.). Statistical significance was assessed by a Student's t-test for the parametric variables, and the Chi-square and Mann-Whitney tests were used for the non-parametric variables. The degree of agree- 


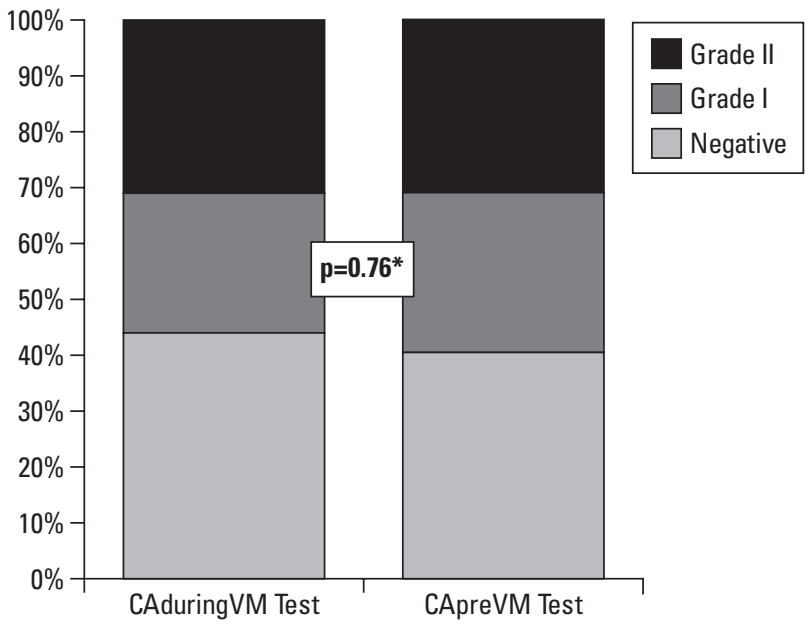

Fig 2. Comparison of two different Valsalva maneuver procedures (CAduringVM test versus CApreVM test) based on microbubble grade (*Mann-Whitney test). Significance $p<0.05$.

ment for a positive test ( $\geq 1 \mathrm{MB}$ ) was tested with the kappa test for agreement. Statistical significance was determined at $\mathrm{p}<0.05$.

\section{RESULTS}

For the 42 patients evaluated, the mean age was $41.6 \pm 11.9$ years old, $52 \%$ were female, and a total of 84 MCA tests with the CAduringVM test and 84 MCA tests with the CApreVM test, none of the patients had any adverse events during or after the tests. From all patients evaluated, 28 presented at least one positive CAduring VM test and 27 presented at least one CApreVM test positive $(\mathrm{p}=0.893)$

Positive tests were observed in 47 (56\%) of the CAduringVM tests and in 50 (59.5\%) of the CApreVM test $(\mathrm{p}=0.64)$. Only two tests were positive with the CAduringVM test and negative with the CApreVM test, while five tests were positive with the CApreVM test and negative with the CAduringVM test. There was an almost perfect agreement for positivity between the CAduringVM test and the CApreVM test, with a correlation $\mathrm{r}_{\mathrm{s}}=0.829$ (95\% CI 0.61-1.00, $\mathrm{p}<0.001$ ). The ET grades were similar in both groups: the CAduringVM test demonstrated 37 (44\%) negative, 21 (25\%) grade I, and $26(31 \%)$ grade II tests, and the CApreVM test demonstrated 34 (40.5\%) negative, 24 (28.6\%) grade I, and 26 (31\%) grade II tests $(\mathrm{p}=0.76)$ (Fig 2).

The mean number of ET $(97.7 \pm 125.6$ in the CAduringVM test versus $77.3 \pm 111.2$ in the CApreVM test, $\mathrm{p}=0.40)$, the latency time in seconds $(10.6 \pm 9.0$ in the CAduringVM test versus $13.5 \pm 5.3$ in the CApreVM test, $\mathrm{p}=0.56$ ), and the duration time of the ET passage in seconds $(18.0 \pm 16.8$ in the CAduringVM test versus $17.9 \pm 16.5$ in the CApreVM test, $\mathrm{p}=0.98$ ) were similar in both groups.

\section{DISCUSSION}

The present study demonstrated that the timing of the VM made no difference when ASb was used as the CA for RLS screening by cTCD. The mean number of ET, the latency time, and the duration did not differ based on the timing of the VM.

Previous studies with different CAs demonstrated that $\mathrm{CA}$ infusion during the VM and before the VM showed good sensitivity values compared to contrast-enhanced transesophageal echocardiography (cTEE) for RLS diagnosis, preferentially for PFO diagnosis ${ }^{1-4,10}$. An international consensus suggested that the VM should start five seconds after the beginning of the CA injection and should be maintained for at least five seconds ${ }^{1}$. This procedure was done in the current study (CApreVM test), and the results demonstrated an almost perfect agreement compared to the CA injection during the VM (CAduringVM test) for positivity of RLS with ASb.

Droste et al. demonstrated that at least two different moments of VM must be done if the first procedure was negative ${ }^{4}$, these results were confirmed by other studies during the PFO diagnosis ${ }^{11}$. In the current study, it was observed that a different procedure changed seven MCA results: two that were negative with the CApreVM test and became positive with the CAduringVM test; five that were negative with the CAduringVM test changed to positive with the CApreVM test.

This study has some limitations. The patients were not submitted to PFO diagnosis by cTEE to identify the sensitivity and specificity for cardiac RLS by this technique. In a previous study, we demonstrated that standardized cTCD is a good method for RLS screening ${ }^{2}$. Another limitation was the use of only ASb; the results could be different with other CA, and until now, no previous comparative analysis has been done. We recently demonstrated that ASb is as good as AS for RLS screening by cTCD (unpublished data).

In conclusion, we agree that the VM procedure used in the current consensus for the diagnosis of RLS by cTCD can be accepted when ASb is used as the CA, but if a negative result is observed, the patient should be submitted to a different protocol with a different timing of the VM, which could involve CA injection during VM (CA duringVM test).

\section{REFERENCES}

1. Jauss M, Zanette E. Detection of right-to-left shunt with ultrasound contrast agent and transcranial doppler sonography. Cerebrovasc Dis 2000;10:490-496.

2. Lange MC, Zetola VF, Souza AM, et al. Transcranial doppler for patent foramen ovale screening: is there a good correlation with transesophageal echocardiography? Arq Neuropsiquiatr 2008;66:785-789.

3. Schwarze JJ, Sander D, Kukla C, Wittich I, Babikian V, Klingelhöfer J. Methodological parameters influence the detection of right-to-left shunts by contrast transcranial doppler. Stroke 1999;30:1234-1239.

4. Droste DW, Siling K, Stypmann J, et al. Contrast transcranial doppler ultra- 
sound in the detection of right-to-left shunts: time window and threshold in microbubble numbers. Stroke 2000;31:1640-1645.

5. Sastry S, Daly K, Chengodu T, McCollum C. Is transcranial doppler for the detection of venous-to-arterial circulation shunts reproducible? Cerebrovasc Dis 2007;23:424-429.

6. Pott F, van Lieshout JJ, Ide K, Madsen P, Secher NH. Middle cerebral artery blood velocity during a Valsalva maneuver in the standing position. J Appl Physiol 2000;88:1545-1550.

7. Moehring MA, Spencer MP. Power m-mode doppler (PMD) for observing cerebral blood flow and tracking emboli. Ultrasound Med Biol 2002;28:49-57.
8. Ringelstein EB, Droste DW, Babikian VL, et al. Consensus on microembolus detection by transcranial doppler ultrasound. Stroke 1998;29:725-729.

9. Saqqur M, Dean N, Schebel M, et al. Improved detection of microbubble signals using power m-mode doppler. Stroke 2004;35:14-17.

10. Zanette EM, Mancini G, De Castro S, Solaro M, Cartoni D, Chiarotti F. Patent foramen ovale and transcranial doppler: comparison of different procedures. Stroke 1996;27:2251-2255.

11. Bickel A, Maihöfner C, Hilz MJ, Heckmann J. A modified Valsalva maneuver increases the detection rate of patent foramen ovale in transcranial sonography. Clin Neurophysiol 2007;118:16-17. 